\title{
Procesos políticos de América Latina. Una lectura crítica del neoliberalismo
}

doi: http://dx.doi.org/10.32870/espiral.v22i63.1676.g1466 Noé Hernández Cortez

Producto del seminario de investigación "Procesos políticos contemporáneos de Latinoamérica", de la FLACSO sede México, se publica el libro titulado Procesos políticos de América Latina. Una lectura crítica del neoliberalismo, coordinado por Daniel Vázquez y Julio Aibar; ambos estudiosos de América Latina, son actualmente profesores-investigadores en la FLACSO, sede México. La pertinencia del libro para el investigador de América Latina radica en tener una visión crítica sobre las políticas neoliberales implementadas por los gobiernos en las tres últimas décadas en el orbe latinoamericano. Como sabemos, el término neoliberalismo en el discurso académico es polivalente, no obstante el presente libro tiene el objetivo de "comprender mejor el neoliberalismo", como se anuncia en la introducción, a través de sus ocho capítulos, a partir del análisis de contextos sociopolíticos específicos, que permitan una mirada particular de los casos estudiados, sin perder la visión de conjunto de la articulación hegemónica del neoliberalismo en América Latina. De ahí que

Profesor-investigador en el Departamento de Administración Pública en la Universidad del Istmo, campus Ixtepec, Oaxaca, México. noe.hernandez@flacso. edu.mx se requiera poner atención a cada uno de los casos expuestos en los capítulos que conforman a la obra aquí reseñada. En "La for-

Daniel Vázquez y Julio Aibar (coords.). (2013). Procesos políticos de América Latina. Una lectura crítica del neoliberalismo. México: FLACSO México. 
mación del orden hegemónico. Límites y aperturas del neoliberalismo en Perú y México”, de Jorge Luis Duárez Mendoza y Fernando Munguía Galeana, los autores indagan sobre la lógica de la hegemonía neoliberal en México y Perú. En México, muestran los autores, la hegemonía del neoliberalismo tiene sus raíces en las reformas con orientación al libre mercado impulsadas a partir del gobierno de Miguel de la Madrid (1982-1988); posteriormente la llamada alternancia política del año 2000 fue más un reacomodo de las élites políticas y económicas, que dio paso a lo que Gramsci llamó "estado ampliado" construido como una "revolución pasiva". Pensar en esta clave la política mexicana es de gran actualidad para tener una brújula conceptual sobre las formas de dominación que se están construyendo en este México reformista. El neoliberalismo en el Perú llega a sedimentarse a través de una amalgama discursiva excéntrica: el gobierno de Fujimori hizo posible darle tintes populistas a su política neoliberal durante sus dos mandatos presidenciales (1990-1995 y 1995-2000), discurso neoliberal que se fue erosionando en su vertiente popular durante el gobierno de Alejandro Toledo (2001-2006). Con el gobierno de Alan García (2006-2011) se agudizaron los antagonismos que engendró el modelo neoliberal entre los agentes “empresariales" y sus enemigos: los "perros" del hortelano. Así, los autores constatan los límites y aperturas políticas en el seno mismo del neoliberalismo.

"El problema del narcotráfico y las formas de ejercer el Estado en México" de Adrián Velázquez es una propuesta teórica para analizar empíricamente la forma "en que se ejerce el Estado en México" en el espacio de la política habitada por las redes del narcotráfico. Adrián Velázquez propone las categorías de discurso y espacio como ejes analíticos para entender cómo el narcotráfico es ante todo un fenómeno político, mediado por las instituciones gubernamentales en México. A esta apuesta teórica, novedosa en 
la Academia mexicana para dar cuenta del problema del narcotráfico, el autor aporta evidencia empírica en cómo se ejerce el Estado en México: un Estado poroso para el narcotráfico; un aparato estatal violador sistemático de los derechos humanos a través de su brazo ejecutor: el ejército mexicano; una agenda pública estatal que durante el gobierno de Felipe Calderón (2006-2012) se concentró en el discurso de la "guerra contra el narcotráfico", que se tradujo en una gran demanda de "recursos materiales y humanos" (p. 88). La cartografía del espacio político de las redes del narcotráfico en México que nos presenta Adrián Velázquez es un diagnóstico puntual sobre las carencias estatales del Estado mínimo y gerencial que exige la ideología neoliberal. Agostina Constantino escribe el "Discurso chacarero y disputas hegemónicas en la pampa argentina”. La autora parte de la distinción entre macrohegemonía y microhegemonía: en la primera se gesta "el 'plano clave' para definir los 'grandes temas sociales"; en la segunda se "abordan las disputas por cuestiones más puntuales, no necesariamente ligadas a los 'grandes temas sociales"' (p. 107). En esa línea argumentativa sostiene la capacidad holística de la microhegemonía a través de las "disputas hegemónicas" que nos permiten hacer visible las luchas por poseer el sentido común de un discurso. En su investigación específicamente resignifica el cambio o continuidad de los discursos de cuatro tipos de sujetos sociales en el agro pampeano argentino: 1) los productores familiares pobres; 2) los chacareros; 3) los capitalistas terratenientes; y 4) los capitalistas arrendatarios. A partir de una meticulosa investigación hemerográfica, Agostina Constantino emprende la tarea de ponderar los discursos de estos cuatro sujetos sociales a través de las disputas hegemónicas en dos etapas históricas de la economía argentina: la de la convertibilidad y la de postdevaluación. Los productores familiares pobres no han cambiado el discurso en ambos períodos y siguen responsabilizando de 
sus problemas al modelo económico argentino. La autora llama la atención en el cambio de discurso de los chacareros, que pasó de ser un discurso de oposición al gobierno en el período de la convertibilidad a construir un discurso cercano al de los capitalistas arrendatarios, más ligado al espíritu empresarial e innovación tecnológica que da un sentido común a la actitud "optimista" frente a la globalización económica. El trabajo de Agostina Constantino es indispensable para comprender las disputas hegemónicas como espacios de luchas por el sentido de un discurso entre los sujetos sociales.

"El conflicto popular de Oaxaca en 2006. Revuelta y comunidad" de Guillermo Pereyra traza la problemática teórica entre revuelta popular y comunidad. Con base en una sólida formación en filosofía política sobre la revuelta popular, comunidad y comunicación, anclada en Maurice Blanchot, Jacques Rancière y Giorgio Agamben, entre otros autores, argumenta que el conflicto oaxaqueño del 2006, articulado en torno a la Asamblea Popular de los Pueblos de Oaxaca (APPO), constituyó un momento de hacer visible la palabra de los excluidos a través de la toma de las radiodifusoras, la televisión estatal y "hasta las tecnologías de libre publicación (correos electrónicos, teléfonos celulares, blogs, sitios web, grafitis)” (p. 144). Como se sabe, el conflicto oaxaqueño dio inicio con la tradicional exigencia sindical de aumento salarial de la sección 22 del Sindicato Nacional de los Trabajadores de la Educación (SNTE); sin embargo, en esta ocasión el gobierno cerró los canales de negociación desembocando en la protesta y posterior resistencia del magisterio. El daño se amplió al hacer visible la corrupción de la autoridad estatal, cuestión que desembocó en exigir la renuncia del gobernador Ulises Ruiz. A esta lucha se sumó lo que en el devenir de los eventos será la APPO. Así, la posterior alianza entre el PRI de Ulises Ruiz y el PAN de Felipe Calderón, desembocó en el uso de la fuerza, en una 
trágica violación de los derechos humanos, por parte de la Policía Federal Preventiva (PFP) al desalojar sistemáticamente las barricadas de las distintas organizaciones que giraban alrededor de la APPO. La revuelta popular de la APPO frente al autoritarismo oaxaqueño, representa "el 'doloroso asomarse' de la existencia 'sobre el abismo de la muerte' [...]” (p. 130). No es de extrañar que el texto de Pereyra no cierre con conclusiones, sino con un apartado abierto a la reflexión -he ahí la textura moral de su texto-, como la palabra abierta que se encontró en los muros de Oaxaca en enero de 2007: “¿De verdad piensas que se acabó todo? Si apenas va a empezar. No ha pasado nada aún” (p. 153).

Daniel Vázquez y Francisco Cantamutto, autores de "El poder empresarial en Argentina: la negociación de la deuda", indagan sobre los poderes fácticos empresariales en Argentina en torno a los procesos políticos de la negociación de la deuda pública. Los autores argumentan que los gobiernos son controlados por la presión de los poderes empresariales, quienes en la hechura de las políticas logran insertar sus propios intereses; esto lo demuestran en el caso paradigmático de la tortuosa negociación de la deuda de Argentina: el blindaje de diciembre de 2000, el megacanje de junio de 2001, el proceso de los préstamos garantizados de noviembre del 2001, la propuesta de Dubai-Buenos Aires de enero a marzo de 2005, la cancelación de la deuda con el Fondo Monetario Internacional (FMI) en enero de 2006, la etapa del Club de París a partir de mayo de 2006 y la reapertura del canje de abril a junio de 2010. Los poderes fácticos que identifican los autores en torno a la renegociación de la deuda en Argentina son: a) los organismos internacionales de crédito, principalmente el FMI; b) los bonistas, "inversores no sofisticados, tenedores mayoritarios de la deuda pública en default" (p. 173); c) grandes fondos de inversión y bancos trasnacionales; d) las Administradoras de Fondos de Jubilaciones y Pensiones (AFJP); e) el sector 
financiero interno; f) la gran burguesía. Lo paradójico es que en el momento de clímax de la renegociación de la deuda, con el canje en 2005 y el pago adelantado de deuda al FMI en el 2006, la gran burguesía, al parecer el gran ganador, articuló su discurso triunfador con el del gobierno, como bien lo dijo en su momento el Presidente Néstor Kirchner: "se trataba de 'reconstruir la burguesía nacional”' (p. 184). La investigación de Daniel Vázquez y Francisco Cantamutto, es fundamental para regresar al estudio de los poderes fácticos en América Latina, abandonados por la academia en los últimos años.

"Los linchamientos en México: una tipología posible" de Leandro Gamallo. El autor muestra cómo los linchamientos en México han aumentado en los últimos años. En cifras: "[...] la presencia de linchamientos en los últimos años se ha intensificado. De los 403 casos del periodo, 118 se produjeron en 2010 y 2011 (un promedio de 59 acciones anuales, un tercio del total)". Para analizar esta frecuencia de la violencia colectiva que conllevan los linchamientos, el autor propone una tipología con base en las aportaciones teóricas de Charles Tilly sobre el grado de coordinación y la relevancia de los daños a corto plazo de la violencia colectiva: 1) grado de coordinación alto, caracterizado por la presencia de acciones ritualizadas; 2) grado de coordinación medio, caracterizado por no presentar acciones ritualizadas, manifiestan "acciones de violencia complejas o acciones de protesta organizadas, presentan metas explícitas o negociación con las fuerzas del orden" (p. 216); 3) grado de coordinación bajo, caracterizado por no presentar acciones ritualizadas, "no presentan acciones de violencia complejas ni acciones de protesta organizadas; no presentan metas explícitas ni negociación con las fuerzas del orden” (p. 216). Esta tipología es de un enorme potencial explicativo sobre las formas en cómo se llevaron a cabo los linchamientos en México en el período 2000-2011, a manera de ejemplo cabe 
mencionar el linchamiento del 2001 ocurrido en Magdalena Petlacalco, delegación Tlalpan, en el Distrito Federal: “[...] la muchedumbre arrastró al sujeto hasta el quiosco de la plaza principal, lo amarraron al barandal y comenzaron a golpearlo [...] continuaron con la golpiza contra el sujeto, hasta que le provocaron la muerte” (p. 216). Este caso narrado por Gamallo da cuenta de los linchamientos con un alto grado de coordinación caracterizado por la presencia de acciones ritualizadas. El trabajo de Gamallo es una mirada sociológica a las formas de linchamientos en México, fenómenos de una gran complejidad social.

Javier Contreras Alcántara escribe "La experiencia democrática en el México contemporáneo: variaciones conceptuales y límites de sentido”. El trabajo de Contreras Alcántara es uno de los primeros esfuerzos sistemáticos por dilucidar los distintos significados del concepto democracia a través de destacados intelectuales como Jesús Silva Herzog, Daniel Cosío Villegas, José Iturriaga, Rafael Segovia, Octavio Paz y Enrique Krauze. Como sabemos, en estos días Por una democracia sin adjetivos (1984) de Krauze, cumple exactamente treinta años de su aparición en la opinión pública mexicana; respecto de este ensayo Contreras Alcántara escribe: "El argumento central era que México había sufrido un 'agravio' y la única manera de solventarlo era con la democracia” (p. 248). Qué entendía Krauze por democracia: "realización de elecciones, conteo de votos y respeto al resultado". Para el poeta Paz la democracia será un "método para plantearlos [los problemas] y entre todos discutirlos". Paz no olvidará que la democracia también es un aprendizaje histórico arraigado en la cultura política. Los nuevos analistas políticos dejan de lado este pensamiento del poeta $\mathrm{Paz}$-nos recuerda Contreras Alcántara- al concentrarse exclusivamente en el ejercicio de la democracia como reglas de juego electorales. El propio 
Krauze en sus últimos escritos ha colocado el concepto de democracia como ejercicio de prácticas políticas:

En la antesala de tal acontecimiento [la alternancia política del 2000], Krauze se da a la tarea de reflexionar sobre las tareas pendientes y señala que, en cuanto a legislación, instituciones y prácticas electorales, el avance era innegable; el problema estaba en la cultura política, en "la matriz de ideas y creencias [...] que permean y norman nuestra vida cotidiana de manera más profunda que las leyes, las prácticas o las instituciones (p. 254).

Julio Aibar y Paula Valle de Bethencourt escriben "Populismo y organicismo: ¿un encuentro natural?”. La investigación de los autores es un diálogo crítico con la obra del historiador italiano Loris Zanatta, estudioso del peronismo. La objeción principal que realizan Aibar y Valle de Bethencourt es que Zanatta articula de manera natural el peronismo, como expresión populista, con una visión organicista de la sociedad:

el populismo es para el autor [Loris Zanatta] una expresión política que se ubicaría dentro de una extensa familia, que va desde los soviets hasta la Cuba castrista -pasando por el franquismo y el fascismo-, y que se define por abrazar un imaginario organicista que consiste esencialmente en concebir a la sociedad como una copia o expresión de la naturaleza (p. 265).

Zanatta sostiene que el peronismo es premoderno, alejado de la modernidad misma consistente en: "la diferenciación y diversificación social y a su expresión política: el liberalismo" (p. 265). Ante la lectura sobre el peronismo de Loris Zanatta, Aibar y Valle de Bethencourt contraponen una lectura del peronismo a través de la reconstrucción discursiva de dos textos claves de Eva Perón: La razón de mi vida y Mi mensaje. El peronismo de Eva Perón es la comunidad 
política de la madre protectora de los "descamisados", los "grasas" y los hijos de las mujeres de su pueblo, campo discursivo de Eva Perón "que busca politizar a una parte de la sociedad" (p.291), he ahí la importancia del peronismo de Eva Perón que apela a su pueblo para naturalizar su discurso de la justicia social, identificando al enemigo en los "oligarcas" de la comunidad política argentina. A diferencia de Zanatta, Aibar y Valle de Bethencourt conciben la expresión populista del peronismo a través del discurso de Eva Perón como el "lenguaje cargado de sensibilidad [...] para codificar la lucha social en el más moderno de los registros: el de los derechos" (p.292). De esta forma, Aibar y Valle de Bethencourt cierran lucidamente esta obra colectiva. Este breve itinerario por la obra Procesos políticos de América Latina. Una lectura crítica del neoliberalismo, nos recuerda la relevancia de construir discursos alternos de explicación social, que abran el debate sobre las distintas facetas que presenta hoy el neoliberalismo en América Latina. Así, con la aparición de este libro tenemos ya un primer y gran paso en esa dirección de explicación crítica. 